\title{
Preparation of $\mathrm{AlB}_{12}$ powder by self-propagating high-temperature synthesis (SHS)
}

\author{
Chao Wang ${ }^{1 *}$, Xiaoming $\mathrm{CaO}^{2}$, Mengge Dong ${ }^{3}$, Lu Zhang ${ }^{4}$, Jianxing Liü ${ }^{3}$ Xiaozhou Cao ${ }^{3}$, and Xiangxin Xue ${ }^{3 *}$ \\ ${ }^{1}$ Department of Mechanical Engineering, the University of Texas at Dallas, Richardson, TX, 75080, USA \\ 2Institute of Metal Research, Chinese Academy of Science, Shenyang, Liaoning, 110016, China \\ ${ }^{3}$ School of Metallurgy, Northeastern University, Shenyang, Liaoning, 110819, China \\ ${ }^{4}$ School of Energy and Environment, Anhui University of Technology, Ma'anshan, 243002, China
}

Chao Wang, Xiaoming Cao, and Mengge Dong made an equal contribution.

*Corresponding author. E-mail: wang.chao@utdallas.edu, xuexx@mail.neu.edu.cn

\section{Keywords: $\mathrm{AlB}_{12}$, SHS, Microstructure, Adiabatic temperature, Component}

\begin{abstract}
Self-propagating high-temperature synthesis (SHS) process is used to prepare $\mathrm{AlB}_{12}$. The phase analysis results of preparing $\mathrm{AlB}_{12}$ with $\mathrm{Al}$ and $\mathrm{B}_{2} \mathrm{O}_{3}$ as raw materials show that under air and argon conditions, the self-propagating and acid-washed self-propagating powders all have $\alpha-\mathrm{Al}_{2} \mathrm{O}_{3}$ impurities when $\mathrm{Mg}, \mathrm{Al}$ and $\mathrm{B}_{2} \mathrm{O}_{3}$ are used as raw materials. The phase analysis results of the preparation of $\mathrm{AlB}_{12}$ show that under argon conditions, the self-propagating and acid-washed, self-propagating powder has un-removable $\mathrm{MgAl}_{2} \mathrm{O}_{4}$ impurities, and the root cause of the low purity of $\mathrm{AlB}_{12}$ prepared by the self-propagating method is the presence of un-removable impurities.
\end{abstract}

\section{Introduction}

Most of the borides are crystals with high hardness and melting point [1-4]. Stable chemical properties and a wide range of applications make it widely used in composite materials, semiconductors, and in various areas of national defense, such as radiation protection [5-8]. Among them, $\mathrm{AlB}_{12}$ has a special electronic structure and bonding characteristics $[9,10]$. It can effectively adjust the conductivity of semiconductor materials, and thus is extensively employed in conductors and semiconductor materials. In addition to the above characteristics, the content of boron in $\mathrm{AlB}_{12}$ is extremely high, reaching $82.8 \%$, which is very promising as neutron shielding material [11-13].

Ceramic powders are usually synthesized by traditional sintering methods [14-16]. However, the use of this method to synthesize ceramic powder takes a long time, consumes a great deal of energy and pollution [17]. Self-propagating high-temperature synthesis (SHS) is a unique technique for synthesizing materials by self-heating and self-conduction of high chemical reaction heat between reactants. This technology was first discovered by Merzhanov et al., in their research on the combustion of solid propellants in rockets and was announced in 1967. Compared with the conventional sintering method, the advantages of the SHS method can be summarized as follows: (1) It is time saving and makes full use of energy [18]. (2) It requires only simple equipment and processes [19]. (3) The high product purity and product conversion rate are close to $100 \%$ [20]. (4) It can not only produce ceramic powder, but if the proper amount of pressure is applied at the same time, high-density combustion products can also be produced [21]. (5) High output [22].

In previous studies, $\mathrm{AlB}_{12}$ powder was fabricated by through the use of the SHS method [23]. The calculation results of preparing $\mathrm{AlB}_{12}$ with $\mathrm{Mg}, \mathrm{Al}_{2} \mathrm{O}_{3}$ and $\mathrm{B}_{2} \mathrm{O}_{3}$ as raw materials show that the adiabatic temperature of the system is $2789.5 \mathrm{~K}$, which satisfies the self-propagating reaction conditions. Further, the phase analysis results show that there is no matter in air or argon, the 
self-propagating powder and the acid-washed self-propagating powder all have $\mathrm{Mg}_{0.4} \mathrm{Al}_{2.4} \mathrm{O}_{4}$ impurities, and the purity of the prepared $\mathrm{AlB}_{12}$ is not high.

Although $\mathrm{AlB}_{12}$ is produced, $\mathrm{Mg}_{0.4} \mathrm{Al}_{2.4} \mathrm{O}_{4}$ has not been removed and still exists. In this paper, $\mathrm{Al}, \mathrm{B}_{2} \mathrm{O}_{3}$ and $\mathrm{Mg}, \mathrm{Al}, \mathrm{B}_{2} \mathrm{O}_{3}$ were used as raw materials to conduct experimental studies on self-propagating synthesis of $\mathrm{AlB}_{12}$.

\section{Experimental procedure}

The starting materials used in this research were $\mathrm{Al}$ powder (purity $>99 \% \mathrm{Al}$, average particle size $50 \mu \mathrm{m}$ ), $\mathrm{B}_{2} \mathrm{O}_{3}$ powder (purity $>99 \%$, average particle size $96 \mu \mathrm{m}$ ), and $\mathrm{Mg}$ powder(purity $>$ $98 \%$, average particle size $100 \mu \mathrm{m})$.

The steps used in the self-propagating process to synthesize $\mathrm{AlB}_{12}$ ceramic powder are as follows: (1) Weigh a certain amount (in proportion to the reaction equation) of the original material powder, place it in the ball milling tank, and mix the ball mill for 2 hours. (2) Intercept the resistance wire and connect it to the two poles of the self-propagating device and place the material in the atmosphere with one end close to the resistance wire. (3) Start the ignition device and slowly increase the current. When the pointer fluctuates sharply, reduce the current and keep the current increasing steadily. Finally, the resistance wire will reach a molten state when the material is induced to burn, and the current is turned off. (4) The reaction product is pulverized and sieved with 160 meshes, and samples under the sieve are sampled for detection and analysis.

This article focuses on the study of two reaction systems, system 1: $\mathrm{Al}$ and $\mathrm{B}_{2} \mathrm{O}_{3}$, and system 2: $\mathrm{Mg}, \mathrm{Al}$, and $\mathrm{B}_{2} \mathrm{O}_{3}$. Two experimental atmospheres are used in both systems (Table 1).

Table 1 The experimental scheme of tests

\begin{tabular}{cccl}
\hline Serial & Reactant & Atmosphere & Pickling condition \\
\hline S1 & $\mathrm{Al}+\mathrm{B}_{2} \mathrm{O}_{3}$ & Air & Before pickling \\
S2 & $\mathrm{Al}+\mathrm{B}_{2} \mathrm{O}_{3}$ & Air & After pickling \\
S3 & $\mathrm{Al}+\mathrm{B}_{2} \mathrm{O}_{3}$ & $\mathrm{Ar}$ & Before pickling \\
S4 & $\mathrm{Al}+\mathrm{B}_{2} \mathrm{O}_{3}$ & $\mathrm{Ar}$ & After pickling \\
S5 & $\mathrm{Mg}+\mathrm{Al}+\mathrm{B}_{2} \mathrm{O}_{3}$ & $\mathrm{Ar}$ & Before pickling \\
S6 & $\mathrm{Mg}+\mathrm{Al}+\mathrm{B}_{2} \mathrm{O}_{3}$ & $\mathrm{Ar}$ & After pickling \\
\hline
\end{tabular}

In the $\mathrm{Al}-\mathrm{B}_{2} \mathrm{O}_{3}$ system, the following chemical reactions mainly occur:

$$
13 \mathrm{Al}+6 \mathrm{~B}_{2} \mathrm{O}_{3} \rightarrow \mathrm{AlB}_{12}+6 \mathrm{Al}_{2} \mathrm{O}_{3}
$$

In the $\mathrm{Mg}-\mathrm{Al}-\mathrm{B}_{2} \mathrm{O}_{3}$ system, the following chemical reactions mainly occur:

$$
\begin{aligned}
3 \mathrm{Mg}+\mathrm{B}_{2} \mathrm{O}_{3} & \rightarrow 2 \mathrm{~B}+3 \mathrm{MgO} \\
\mathrm{Al}+12 \mathrm{~B} & \rightarrow \mathrm{AlB}_{12} \\
18 \mathrm{Mg}+\mathrm{Al}+6 \mathrm{~B}_{2} \mathrm{O}_{3} & \rightarrow \mathrm{AlB}_{12}+18 \mathrm{MgO}
\end{aligned}
$$

After the combustion synthesis, the extraneous components were leached out from the synthesized powder with $60^{\circ} \mathrm{C}$ in diluted $\mathrm{HCl}$. The phase analysis of the synthesized powder was carried out using an X-ray diffractometer (XRD, X'Pert Pro MRD) with a Philips diffractometer 
using $\mathrm{Cu} \mathrm{Ka}$. The microstructure of powders was investigated using a scanning electron microscope (SEM, S-3400N).

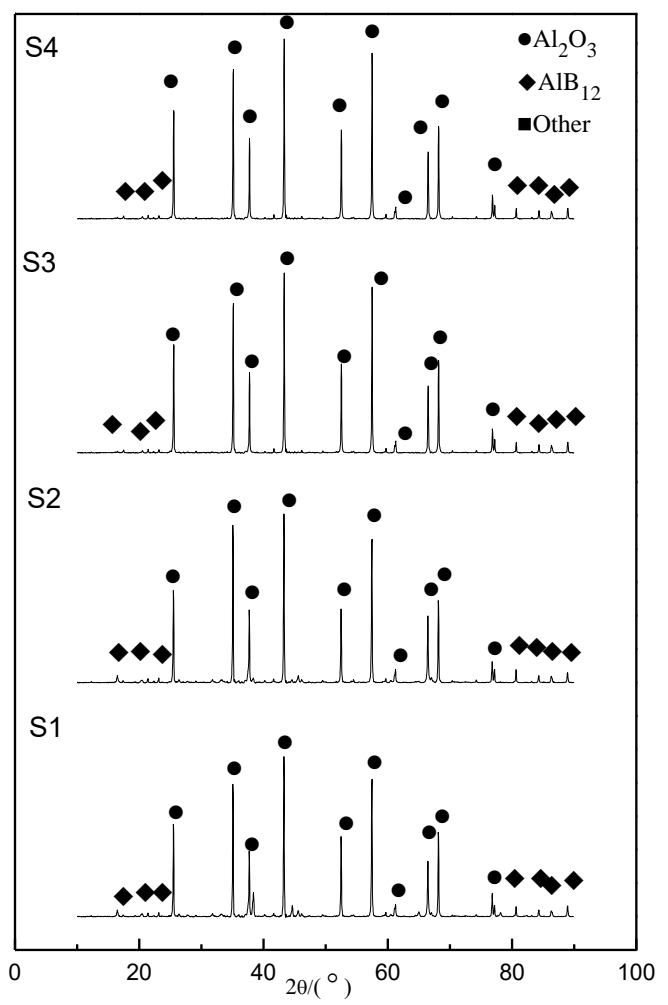

Fig. 1 XRD patterns of fabrication $\mathrm{AlB}_{12}$ from $\mathrm{Al}$ and $\mathrm{B}_{2} \mathrm{O}_{3}$

\section{Results and discussion}

Figure 1 is the $\mathrm{X}$-ray diffraction pattern of $\mathrm{Al}$ and $\mathrm{B}_{2} \mathrm{O}_{3}$ prepared under both air conditions (before and after pickling) and argon conditions (before and after pickling) respectively. It can be seen from the figure that in either air or argon conditions, irremovable $\mathrm{Al}_{2} \mathrm{O}$ is found in the bottom3. Analysis of its crystal structure revealed that the $\alpha-\mathrm{Al}_{2} \mathrm{O}_{3}$ is corundum, an extremely stable substance that is difficult to remove through physical and chemical reactions. Therefore, $\mathrm{AlB}_{12}$ prepared from $\mathrm{Al}$ and $\mathrm{B}_{2} \mathrm{O}_{3}$, contains a large amount of inseparable corundum, which contributes to the failure of the self-propagating preparation of $\mathrm{AlB}_{12}$ using $\mathrm{Al}$ and $\mathrm{B}_{2} \mathrm{O}_{3}$ as raw materials.

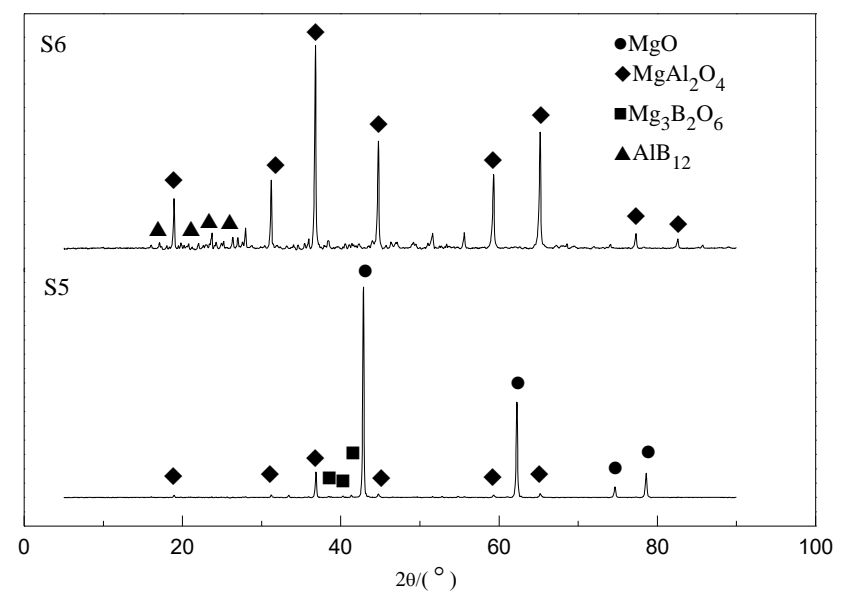

Fig. 2 XRD patterns of fabrication $\mathrm{AlB}_{12}$ from $\mathrm{Mg}, \mathrm{B}_{2} \mathrm{O}_{3}$ and $\mathrm{Al}_{2} \mathrm{O}_{3}$ 
Figure 2 is the $\mathrm{X}$-ray diffraction pattern of powder prepared with $\mathrm{Mg}, \mathrm{Al}$ and $\mathrm{B}_{2} \mathrm{O}_{3}$ under argon conditions (before pickling). From the results of phase analysis, the main components of the coarse powder before pickling are $\mathrm{MgO}, \mathrm{Mg}_{3} \mathrm{~B}_{2} \mathrm{O}_{6}, \mathrm{MgAl}_{2} \mathrm{O}_{4}$, and $\mathrm{AlB}_{12}$, while in the powder after pickling, when $\mathrm{MgO}$ and $\mathrm{Mg}_{3} \mathrm{~B}_{2} \mathrm{O}_{6}$ are removed, the main impurity is $\mathrm{MgAl}_{2} \mathrm{O}_{4}$. This shows that the purity of $\mathrm{AlB}_{12}$ is not high when prepared by self-propagating, self-propagation when the raw materials used are $\mathrm{Mg}, \mathrm{Al}$ and $\mathrm{B}_{2} \mathrm{O}_{3}$.

Figure 3 shows the microscopic morphology of powder prepared through use of the self-propagating method under argon conditions with $\mathrm{Al}$ and $\mathrm{B}_{2} \mathrm{O}_{3}$ as raw materials after pickling. From an analysis of the energy spectrum results, the A particles - with obvious layering phenomenon on the left are $\mathrm{Al}_{2} \mathrm{O}_{3}$ particles - while the $\mathrm{B}$ particles - with more obvious granular shape on the right - are $\mathrm{AlB}_{12}$. This situation shows that despite the pickling treatment, $\mathrm{Al}_{2} \mathrm{O}_{3}$ is still untreated. It also shows that the unremovable by-product $\mathrm{Al}_{2} \mathrm{O}_{3}$ uses $\mathrm{Al}$ and $\mathrm{B}_{2} \mathrm{O}_{3}$ as raw materials and is the biggest obstacle to self-propagating preparation of $\mathrm{AlB}_{12}$.
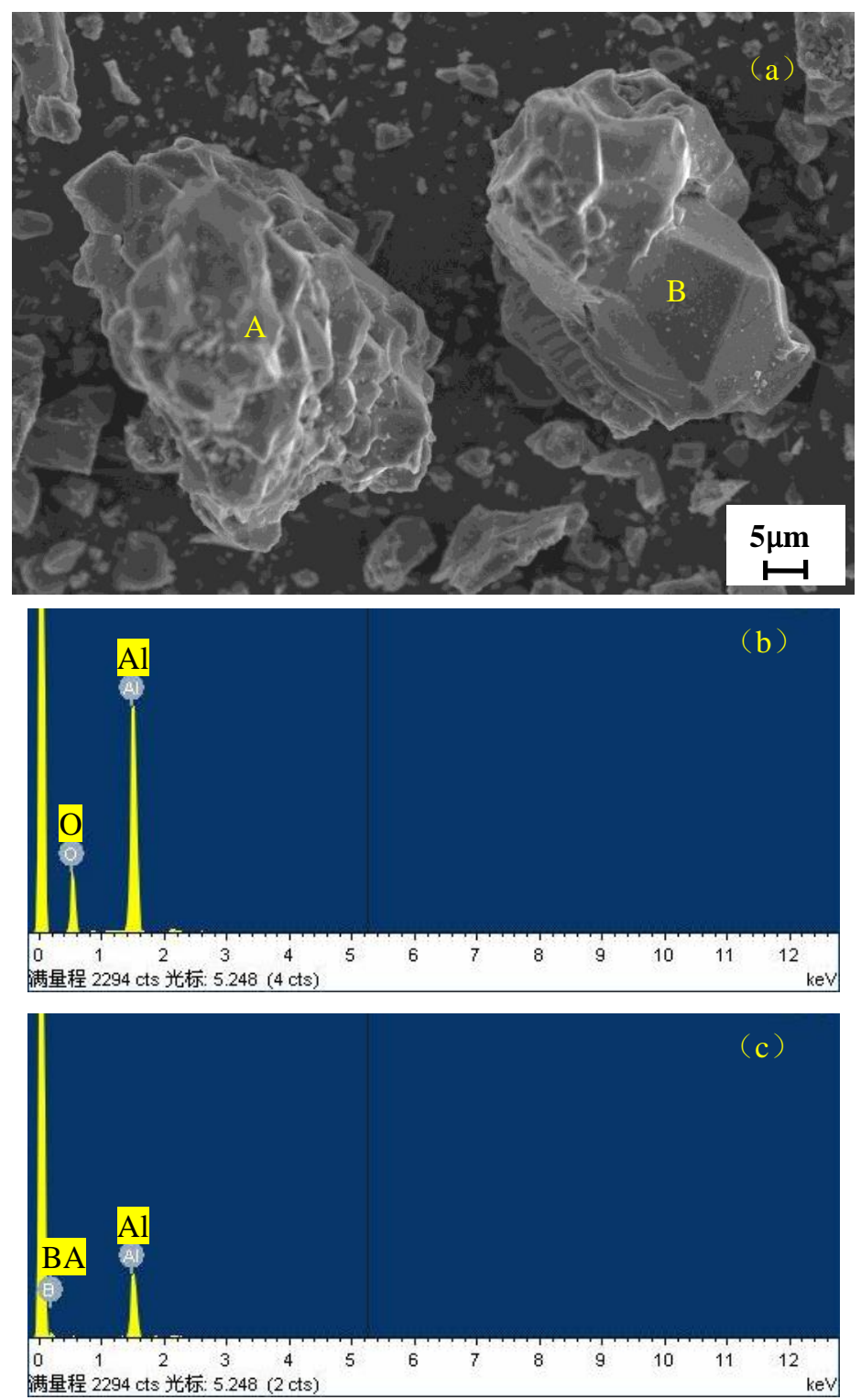

Fig. 3 (a): Microstructure photographs of powder by SHS; (b): EDS analysis of A area; (c): EDS analysis of B area

Table 2 shows the elemental analysis results after pickling of $\mathrm{Al}$ and $\mathrm{B}_{2} \mathrm{O}_{3}$ as raw materials and self-propagating preparation of $\mathrm{AlB}_{12}$ with $\mathrm{Mg}, \mathrm{Al}$, and $\mathrm{B}_{2} \mathrm{O}_{3}$ as raw materials. From the results in the table, the acid wash product prepared with the use of $\mathrm{Al}$ and $\mathrm{B}_{2} \mathrm{O}_{3}$ as raw materials has the highest 
content of $\mathrm{O}$ element, followed by $\mathrm{B}$ and $\mathrm{Al}$. Observing the test samples, there are still insoluble substances, so the test results are also relatively incomplete. This shows that under argon conditions, using $\mathrm{Al}$ and $\mathrm{B}_{2} \mathrm{O}_{3}$ as raw materials to prepare $\mathrm{AlB}_{12}$, and using the self-propagating method, the purity of $\mathrm{AlB}_{12}$ in the prepared product is low, and the $\mathrm{B}$ content is insufficient.

Table 2 The results of elementary analysis (mass fraction, \%)

\begin{tabular}{ccccc}
\hline Serial & $\mathrm{B}$ & $\mathrm{Mg}$ & $\mathrm{Al}$ & $\mathrm{O}$ \\
\hline S4 & 12.6 & - & 2.21 & 85.19 \\
S6 & 58.5 & 9.62 & 3.43 & 28.45 \\
\hline
\end{tabular}

\section{Summary}

The phase analysis results of preparing $\mathrm{AlB}_{12}$ using $\mathrm{Al}$ and $\mathrm{B}_{2} \mathrm{O}_{3}$ as raw materials shows that there are $\alpha-\mathrm{Al}_{2} \mathrm{O}_{3}$ impurities in the self-propagating powder regardless of either the air condition or the argon condition, and it cannot be removed. Consequently, the purity of the prepared $\mathrm{AlB}_{12}$ is not high. The phase analysis results of preparing $\mathrm{AlB}_{12}$ using $\mathrm{Mg}, \mathrm{Al}$ and $\mathrm{B}_{2} \mathrm{O}_{3}$ as raw materials indicates that the self-propagating and acid-washed self-propagating powder has unremovable $\mathrm{MgAl}_{2} \mathrm{O}_{4}$ impurities under argon conditions, and the purity of the prepared $\mathrm{AlB}_{12}$ is not high, causing self-propagation. The fundamental reason for the low purity of $\mathrm{AlB}_{12}$ prepared by this method is the existence of impurities that cannot be removed.

\section{Notes}

The authors declare that they have no competing financial interest.

\section{Acknowledgements}

This work was supported by the fundamental, scientific-research business resources of the central universities (award \# N10060200).

\section{References}

[1] C. Wang, X. Xue, X. Cao, H. Yang, Effect of BN Addition on Mechanical Properties and Microstructure of $\mathrm{TiB}_{2}-\mathrm{Al}$ Composites, Journal of Northeastern University (Natural Science), (2012) 19.

[2] X. Cao, C. Wang, L. Shi, H. Yang, X. Xue, H. Li, Effect of Ni addition on pressureless sintering of tungsten diboride, International Journal of Refractory Metals and Hard Materials, 41 (2013) 597-602. [3] X. Cao, C. Wang, X. Xue, H. Yang, Preparation of tungsten boride ceramic by pressureless sintering, Journal of Inorganic Materials, 29 (2014) 498-502.

[4] V.I. Matkovich, Boron and refractory borides, Springer, 1977.

[5] X. Cao, C. Wang, X. Xue, G. Cheng, Effect of ti addition on the residual aluminium content and mechanical properties of the $\mathrm{B}_{4} \mathrm{C}$-al composites produced by vacuum infiltration, Archives of Metallurgy and Materials, 60 (2015) 2493-2398.

[6] M. Dong, X. Xue, H. Yang, D. Liu, C. Wang, Z. Li, A novel comprehensive utilization of vanadium slag: as gamma ray shielding material, Journal of hazardous materials, 318 (2016) 751-757.

[7] D. Qi, G. Yong, R. Zhiheng, C. Xiaoming, W. Chao, Z. Jinsong, Preparation and Erosion Performance for Co-continuous Phase Composites of $\mathrm{Si}_{3} \mathrm{~N}_{4} / 1 \mathrm{Cr} 18 \mathrm{Ni}$ Ti, Chinese Journal of Materials Research, 33 (2019) 34-42. 
[8] X. Cao, H. Wang, X. Meng, C. Wang, H. Yang, X. Xue, High temperature electrochemical synthesis of tungsten boride from molten salt, Advanced Materials Research, Trans Tech Publ, 2011, pp. 463-466.

[9] D. Gosset, M. Guery, B. Kryger, Thermal properties of some boron - rich compounds ("BnC" and AlB 12), AIP Conference Proceedings, American Institute of Physics, 1991, pp. 380-383.

[10] C. Wang, X. Cao, T. Jiang, Y. Rong, J. Zhang, H. Yang, X. Xue, Research Progress on Aluminum-Boron Compounds (Al-B) and Its Composite Materials, Bulletin of the Chinese Ceramic Society, (2013) 26.

[11] I. Higashi, Crystal chemistry of $\alpha-\mathrm{AlB}_{12}$ and $\gamma-\mathrm{AlB}_{12}$, Journal of solid state chemistry, 154 (2000) 168-176.

[12] V. Mahesh, P.S. Nair, T. Rajan, B. Pai, R. Hubli, Processing of surface-treated boron carbide-reinforced aluminum matrix composites by liquid-metal stir-casting technique, Journal of composite materials, 45 (2011) 2371-2378.

[13] M. Mahmoudi, C. Wang, S. Moreno, S.R. Burlison, D. Alatalo, F. Hassanipour, S.E. Smith, M. Naraghi, M. Minary-Jolandan, Three-Dimensional Printing of Ceramics through "Carving" a Gel and "Filling in" the Precursor Polymer, ACS Applied Materials \& Interfaces, 12 (2020) 31984-31991.

[14] X. Luo, Z. Wang, X. Hu, Z. Shi, B. Gao, C. Wang, G. Chen, G. Tu, Influence of metallic additives on densification behaviour of hot-pressed TiB2, Light Metals, (2009) 1151-1155.

[15] C. Wang, M.E. Hossain Bhuiyan, S. Moreno, M. Minary-Jolandan, Direct-Write Printing Copper-Nickel $(\mathrm{Cu} / \mathrm{Ni})$ Alloy with Controlled Composition from a Single Electrolyte Using Co-Electrodeposition, ACS Applied Materials \& Interfaces, 12 (2020) 18683-18691.

[16] W. Chao, X. Xiangxin, C. Xiaozhou, Z. Lu, Z. Jian, Y. He, C. Gongjin, A New Method of Fabricating AlN-TiB2 Composite Ceramics, Materials and manufacturing processes, 28 (2013) 953-956.

[17] W. Chao, X. Xiangxin, C. Xiaozhou, Y. He, C. Gongjin, The effect of Ti addition on the microstructure and fracture toughness of $\mathrm{BN}-\mathrm{Al}$ composite materials synthesized by vacuum infiltration, Archives of Metallurgy and Materials, 58 (2013) 509--512.

[18] X. Cao, L. Xu, C. Wang, S. Li, D. Wu, Y. Shi, F. Liu, X. Xue, Electrochemical Behavior and Electrodeposition of Sn Coating from Choline Chloride-Urea Deep Eutectic Solvents, Coatings, 10 (2020) 1154.

[19] W. Tao, Z. Wang, G. Chen, Z. Shi, B. Gao, X. Hu, C. Wang, Finite element analysis of thermo-electric coupled field in 400kA large-scale aluminum reduction cell, 2009 World Non-Grid-Connected Wind Power and Energy Conference, IEEE, 2009, pp. 1-4.

[20] J. Subrahmanyam, M. Vijayakumar, Self-propagating high-temperature synthesis, Journal of Materials Science, 27 (1992) 6249-6273.

[21] A. Merzhanov, History and recent developments in SHS, Ceramics international, 21 (1995) 371-379.

[22] V. Yukhvid, Modifications of SHS processes, Pure and Applied Chemistry, 64 (1992) 977-988.

[23] C. Wang, B. Ma, L. Zhang, X. Cao, H. Yang, X. Xue, Elementary research on preparation of $\mathrm{AlB}_{12}$ powder by self-propagating high-temperature synthesis (SHS), Materials Science Forum, Trans Tech Publ, 2014, pp. 365-369. 